\title{
Model Kuantisasi Kedua Hamiltonian Resonansi Plasmon Permukaan Terlokalisasi pada Nanologam Bola
}

\author{
M. Siddiq Ilyas L ${ }^{*}$, Zulfi $^{* *}$, Muldarisnur ${ }^{* *}$ \\ Laboratorium Komputer, Jurusan Fisika \\ Fakultas Matematika dan Ilmu Pengetahuan Alam Universitas Andalas \\ Kampus Unand Limau Manis, Padang, 25163 Indonesia \\ *ilyassiddiq55@gmail.com, ${ }^{* *}$ zulfiabdullah@unand.gmail.com ${ }^{* *}$ mrisnur@gmail.com
}

\begin{abstract}
ABSTRAK
Telah diteliti hubungan dispersi pada nanologam bola menggunakan model kuantisasi kedua Hamiltonian (KKH). Hubungan dispersi (HD) diperoleh untuk mengetahui frekuensi resonansi (FR) plasmon pada permukaan bidang batas dielektrik-logam. Sebelumnya, telah diteliti HD pada nanologam planar dan nanowires menggunakan KKH. Pada penelitian lain, juga telah diteliti HD pada nanologam bola (NB) menggunakan persamaan elektrodinamika klasik Maxwell, hasil yang diperoleh adalah FR meningkat pada nilai frekuensi cahaya tinggi saat berinteraksi dengan bidang batas dielektrik-logam. HD juga dapat ditentukan pada geometri NB. Dan pada penelitian ini HD pada NB ditentukan dengan model KKH, kemudian ditransformasi menggunakan transformasi Bogoliubov (TB). FR pada NB meningkat pada rentang energi cahaya tampak yang tinggi, ukuran NB yang lebih kecil, dan pada bilangan kuantum $l$ lebih besar. Hasil tersebut sesuai dengan HD yang diperoleh dari persamaan elektrodinamika klasik Maxwell. Dan HD pada planar dan nanowires lebih kecil dibandingkan HD pada NB.

Kata kunci: kuantisasi kedua Hamiltonian, transformasi Bogoliubov, nanologam bola, hubungan dispersi.
\end{abstract}

\section{ABSTRACT}

Metallic nanosphere dispersion relation has been studied using Hamiltonian second quantization (KKH) model. Dispersion relation (HD) was determined to revealed resonance frequency of plasmon in dielectric-metal interface. Dispersion relation was determined in planar and nanowires metal using KKH before. Another research, $H D$ was determined in metallic nanosphere (NB) using Maxwell classical electrodynamics, the result $F R$ increased in higher visible light while it interacted with dielectric-metal interface. $H D$ was able determined in NB. It's $H D$ was determined by KKH model. Then, it was transformed by Bogoliubov transformastion (TB). FR in NB increased with higher visible light energy, smaller NB size, and higher quantum number $l$. The result was appropriate with $H D$ who is determined from Maxwell classical electrodynamics. Planar and nanowires HD smaller than NB.

Keywords :Hamiltonian second quantization, Bogoliubov transformation, metallic nanopshere, and dispersion relation.

\section{PENDAHULUAN}

Plasmon permukaan (PP) didefinisikan sebagai osilasi elektron koheren yang membentuk gelombang densitas muatan permukaan pada bidang batas logam-dielektrik. Gelombang densitas muatan PP pada frekuensi optik tidak dapat diamati secara eksperimen. Istilah plasmon di sini secara teori merupakan gelombang cahaya yang dibatasi pada bidang batas logam-dielektrik (Zayats dkk., 2003). Hasil eksitasi PP adalah plasmon polariton permukaan (PPP) dan resonansi plasmon permukaan terlokalisasi (RPPT). RPPT merupakan eksitasi elektron konduksi pada logam yang tidak menyebar ke permukaan bahan ketika terkopel dengan medan elektromagnet. Fisis dari RPPT pada permukaan bola ketika terkopel dengan medan akan memberikan gaya pemulih pada elektron bebas logam sehingga menimbulkan resonansi.

Sifat plasmon digambarkan dengan formulasi persamaan Maxwell elektrodinamika klasik. Shopa (2013) melakukan penelitian terhadap nanologam emas Au untuk menemukan solusi persamaan elektrodinamika klasik. HD berguna untuk menentukan sifat dasar dari penyeberan plasmon permukaan pada bidang batas suatu geometri, seperti frekuensi resonansi plasmon, redaman plasmon, dan vektor gelombang momentum (Schider dkk., 2003). Juga dapat mengetahui distribusi intensitas gelombang elektromagnetik (EM) (Brodin dkk., 2006).

Nga dkk (2015) dan Lan dkk (2016) menggunakan persamaan mekanika kuantum dalam menentukan hubungan dispersi. Mekanika yang digunakan dapat mempermudah bahasa kuantum (Stoof dkk., 2008), dengan menguantisasi energi-energi keadaan masing-masing 
partikel. Persamaan tersebut adalah mekanika kuantisasi kedua Hamiltonian (KKH). Mereka memperoleh hubuungan dispersi untuk geometri planar dan nanowire dengan menggunakan KKH. Operator-operator keadaan Hamiltonian didiagonalisasi menggunakan transformasi Bogoliubov (TB).

Hasil yang diperoleh oleh Shopa (2013) adalah frekuensi resonansi plasmon akan meningkat seiring dengan semakin kecilnya ukuran nanopartikel bola logam dan bilangan kuantisasi $l$ yang semakin besar akan meningkatkan besar frekuensi resonansi plasmon. Hasil yang secara tidak langsung diperoleh Nga dkk (2015) dan Lan dkk(2016) walaupun dengan geometri yang berbeda. Nilai frekuensi plasmon ternormalisasi semakin tinggi dengan besarnya vektor gelombang di permukaan bahan. Nilai frekeunsi resonansi menuju konstan pada batas bawah ketika vektor gelombang ternormalisasi semakin besar.

Pada penelitian ini, HD nanopartikel logam bola emas akan ditentukan menggunakan persamaan KKH dan ditransformasi menggunakan TB.

\section{METODE}

Penurunan persamaan KKH dilaksanakan di Laboratorium Komputer jurusan fisika, FMIPA dan Perpustakaan Pusat Universitas Andalas. Langkah-langkah penentuan HD pada penelitian ini adalah

\subsection{Pemodelan kuantisasi kedua Hamiltonian}

Pada langkah ini, keadaan interaksi medan EM dengan material NB dielektrik-logam diturunkan melalui Lagrangian dan kemudian diubah ke dalam Hamiltonian.

\subsection{Integrasi Hamiltonian}

Setelah persamaan interaksi medan EM dan material NB dihasilkan, langkah selanjutnya mengintegrasi masing-masing keadaan energi masing-masing partikel saat interaksi.

\subsection{Diagonalisasi menggunakan transformasi Bogoliubov}

Persamaan KKH yang telah diperoleh dari hasil integrasi masing-masing keadaan, setelah itu didiagonalisasi kedadaan KKH enggunakan TB.

\subsection{Pemograman dengan MATLAB}

Pemograman dilakukan untuk menghasilkan kurva HB. Hubungan antara FR dalam fungsi vektor gelombang ternormalisasi, nilai riil dan imajiner medium dielektrik dalam fungsi FR, dan HD bergantung pada ukuran NB.

\subsection{Analisis hubungan dispersi}

HD pada NB akan dianalisa dengan beberapa hasil penelitian sebelumnya seperti KKH pada planar dan nanowire. Kemudian, HD yang diperoleh dari hasil penelitian Shopa (2013).

\section{HASIL DAN DISKUSI}

\subsection{Hasil pemodelan KKH}

Lagrangian $L$ dari kasus interaksi medan EM dan bahan

$$
L=\frac{1}{2} m \mathbf{v}^{2}+e \mathbf{v} \cdot \mathbf{A}-e \Phi
$$

$m$ adalah massa nanologam, kecepatan partikel $\mathbf{v}$, potensial vektor $\mathbf{A}$, muatan elektron $e$, dan $\Phi$ adalah potensial skalar. Dalam Hamiltonian menjadi

$$
H=\frac{1}{2 m}[\mathbf{p}-e \mathbf{A}(\mathbf{r}, t)]^{2}+e \Phi(\mathbf{r}, t)
$$

dimana p momentum partikel. HKK pada Pers. (2) menjadi

$$
\hat{H}=\hat{H}_{\text {bahan }}+\hat{H}_{r a d}+\hat{H}_{\text {in }}
$$

Hamiltonian dari faktor pertama terdapat pada bahan, medan radiasi elektromagnet (EM), dan interaksi bahan-medan EM. Masing-masing faktor adalah hasil dari integrasi 


$$
\begin{gathered}
\hat{H}_{\text {bahan }}=\int d^{3} \mathbf{r} \hat{\psi}^{+}(\mathbf{r}, t)\left[-\frac{\hbar^{2}}{2 m} \nabla^{2}+U(\mathbf{r})\right] \hat{\psi}(\mathbf{r}, t) \\
\hat{H}_{r a d}=\int d^{3} \mathbf{r}\left(\frac{\varepsilon_{0}}{2}\left(\frac{\partial \mathbf{A}(\mathbf{r}, t)}{\partial t}\right)^{2}+\frac{1}{2 \mu_{0}}(\nabla \times \mathbf{A}(\mathbf{r}, t))^{2}\right) \\
\hat{H}_{i n}=\int d^{3} \mathbf{r} \hat{\psi}^{+}(\mathbf{r}, t)\left[-\frac{e}{m} \mathbf{A}(\mathbf{r}, t) \cdot(-i \hbar \nabla)-\frac{e}{2 m}(-i \hbar \nabla) \cdot \mathbf{A}(\mathbf{r}, t)\right] \hat{\psi}(\mathbf{r}, t)
\end{gathered}
$$

Persamaan operator gelombang $\hat{\psi}(\mathbf{r}, t)=\sum_{\alpha} \hat{c}_{\alpha} e^{-i \ddot{o}_{\alpha} t / \hbar} \phi_{\alpha}(\mathbf{r})$.

\subsection{Hasil integrasi Hamiltonian}

Persamaan linier TB adalah sebagai berikut

$$
\gamma_{i k}=u_{k} a_{k}+v_{k} b_{k}=-v_{k} a_{k}+u_{k} b_{k}
$$

dimana $u_{k}$ dan $v_{k}$ adalah syarat unit uniter, $u_{k}^{2}+v_{k}^{2}=1$.

Hasil integrasi Pers. (4) sampai Pers. (6), diperoleh

$$
\hat{H}=\sum_{\alpha} \grave{\mathrm{o}}_{\alpha} \hat{c}_{\alpha}^{+} \hat{c}_{\alpha}+\sum_{\mathbf{k} s} E_{\mathbf{k s}} \hat{a}_{\mathbf{k s}}^{+} \hat{a}_{\mathbf{k s}}+\sum_{\alpha \beta \mathbf{k s}} g\left(\hat{a}_{\mathbf{k s}} \hat{c}_{\beta}^{+} \hat{c}_{\alpha}+\hat{a}_{\mathbf{k s}}^{+} \hat{c}_{\beta}^{+} \hat{c}_{\alpha}\right)
$$

$\hat{c}_{\alpha}$ adalah operator kedaaan medan EM, $\hat{a}_{\mathrm{ks}}$ operator keadaan plasmon pada permukaan bahan, $\grave{\mathrm{o}}_{\alpha}$ energi radiasi medan EM, $E_{\boldsymbol{k}}$ energi plasmon pada permukaan bahan, dan $g$ konstanta kopling. Pada bab selanjutnya akan dibahas hasil diagonalisasi dengan TB.

\subsection{Hubungan dispersi}

Pada Pers. (8) didiagonalisasi menjadi persamaan matriks sebagai berikut

$$
H=\sum_{z=1, \mathbf{k}=1}\left(\begin{array}{ll}
\gamma_{1}^{+} & \gamma_{1 s}
\end{array}\right)\left(\begin{array}{ll}
u_{1} & v_{1 s} \\
v_{1 s} & u_{1}
\end{array}\right)\left(\begin{array}{cc}
g & \grave{o}_{\alpha} \\
E_{\mathbf{k s}} & g
\end{array}\right)\left(\begin{array}{ll}
u_{1} & v_{1 s} \\
v_{1 s} & u_{1}
\end{array}\right)\left(\begin{array}{l}
\gamma_{1} \\
\gamma_{1 s}^{+}
\end{array}\right)
$$
adalah

Hubungan dispersi $\Omega_{1,2}$ diperoleh dengan mendiagonalisasi Pers. (9), maka hasilnya

$$
\Omega_{1,2}=\frac{1}{2}\left[\left(\grave{\mathrm{o}}_{\alpha}+E_{\mathbf{k s}}\right) \pm \sqrt{\left(\grave{\mathrm{o}}_{\alpha}-E_{\mathbf{k s}}\right)^{2}+4 g^{2}}\right]
$$

\subsection{Hasil pemograman HD dengan Matlab}

Pada Gambar 1 terdapat dua buah kurva cabang atas (garis-titik bulat biru) dan kurva cabang bawah (garis-bintang biru). Nilai fraksi momentum cahaya terhadap momentum pada permukaan plasmonik meningkat dari satu ke titik antara 6 dan 8 .

Setelah itu, grafik memperoleh nilai yang stagnan menuju tak hingga pada hubungan dispersi (perbandingan pada persamaan hubungan dispersi terhadap energi plasmon permukaan) antara nilai $0,55 \leq \Omega_{L k} / E_{p k} \geq 7$. Gambar 1 memiliki keidentikan dengan hasil di mana titik konstan di sumbu-y terjadi ketika fraksi $5 \leq k / k_{p} \geq 7$.

Gambar 2 menjelaskan nilai hubungan dispersi yang berkaitan dengan nilai momentum gelombang vektor dengan nilai rentang cahaya sinar tampak 1,8-3,2 eV. Frekuensi ternormalisasi cabang bawah adalah $\Omega_{1=1 ; \epsilon=3.2 \mathrm{eV}}=1,16, \Omega_{\mathrm{l}=2 ; \epsilon=3.2 \mathrm{eV}}=1,58$, dan $\Omega_{\mathrm{l}=1 ; \epsilon=3.2 \mathrm{eV}}=1,98$, dan pada cabang atas $\Omega_{\mathrm{l}=1 ; \epsilon=3.2 \mathrm{eV}}=1,98, \Omega_{\mathrm{l}=2 ; \epsilon=3.2 \mathrm{eV}}=3,0, \Omega_{\mathrm{l}=3 ; \epsilon=3.2 \mathrm{eV}}=3,70$. Artinya, dengan bertambahnya bilangan kuantum $l$ plasmon terlokalisasi maka akan menyebabkan hubungan dispersi/frekuensi resonansi plasmon akan bertambah. Pada grafik ini, ukuran plasmonik belum termasuk ke dalam persamaan hubungan dispersi. Oleh karena itu, besar vektor gelombang ternormalisasi $k / k_{p l=1 ; \epsilon=3.2 \mathrm{eV}}=12,45$ untuk setiap bilangan kuantum $l$. 


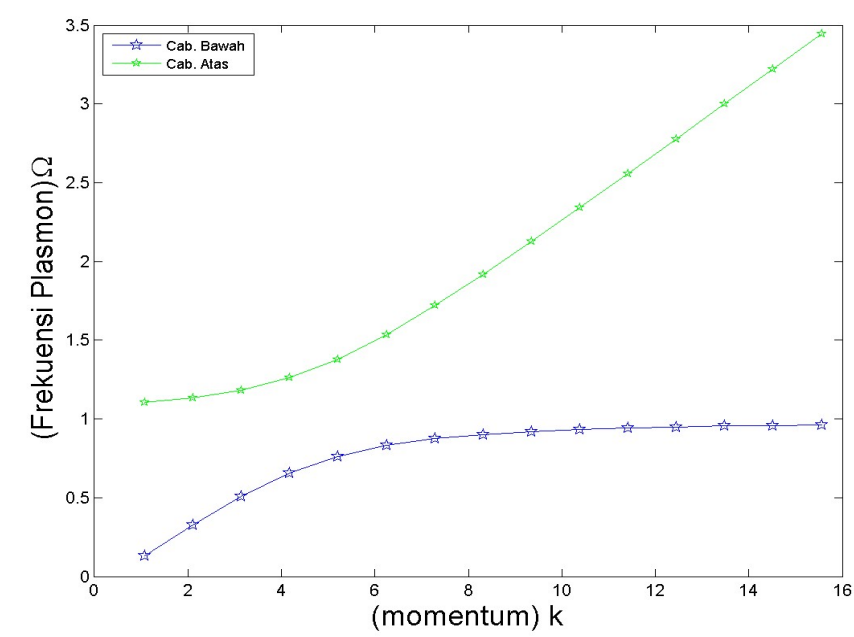

Gambar 1 Grafik hubungan dispersi cabang bawah dan atas. Kurva titik bintang biru untuk cabang bawah dan titik bintang hijau untuk cabang atas.

Hubungan dispersi geometri planar tidak sampai menyentuh nilai 0,8 dengan nilai konstanta kopling $g_{k}$ tertinggi 0,3 . Hubungan dispersi pada cabang atas identik dengan bentuk geometri silinder. Salah satu lapisan yang digunakan adalah Ag (7,3 eV) (Giangregorio dkk, 2015) dan InSb ( 1,8 THz) (Lan dkk, 2016) yang menghasilkan hubungan dispersi cabang bawah sama dengan hasil hubungan dispersi dari Nga dkk (2015). Maka, grafik hubungan dispersi pada planar, nanowire, dan nanologam bola memiliki daerah awal lengkung yang berbeda. Kurva planar lebih dahulu melengkung yang artinya nilai momentum vektor gelombang $k$ yang lebih rendah di bandingkan nanowire dan bola. Sebaliknya, posisi kelengkungan terhadap sumbu-x vektor gelombang terjadi pada grafik HD nanologam bola emas.

Hubungan dispersi geometri planar tidak sampai menyentuh nilai 0,8 dengan nilai konstanta kopling $g_{k}$ tertinggi 0,3 . Hubungan dispersi pada cabang atas identik dengan bentuk geometri silinder. Salah satu lapisan yang digunakan adalah $\mathrm{Ag}(7,3 \mathrm{eV})$ (Giangregorio dkk, 2015) dan InSb $(\sim 1,8 \mathrm{THz})$ (Lan dkk, 2016) yang menghasilkan hubungan dispersi cabang bawah sama dengan hasil hubungan dispersi dari Nga dkk (2015). Maka, grafik hubungan dispersi pada planar, nanowire, dan nanologam bola memiliki daerah awal lengkung yang berbeda. Kurva planar lebih dahulu melengkung yang artinya nilai momentum vektor gelombang $k$ yang lebih rendah di bandingkan nanowire dan bola. Sebaliknya, posisi kelengkungan terhadap sumbu-x vektor gelombang terjadi pada grafik HD nanologam bola emas. 


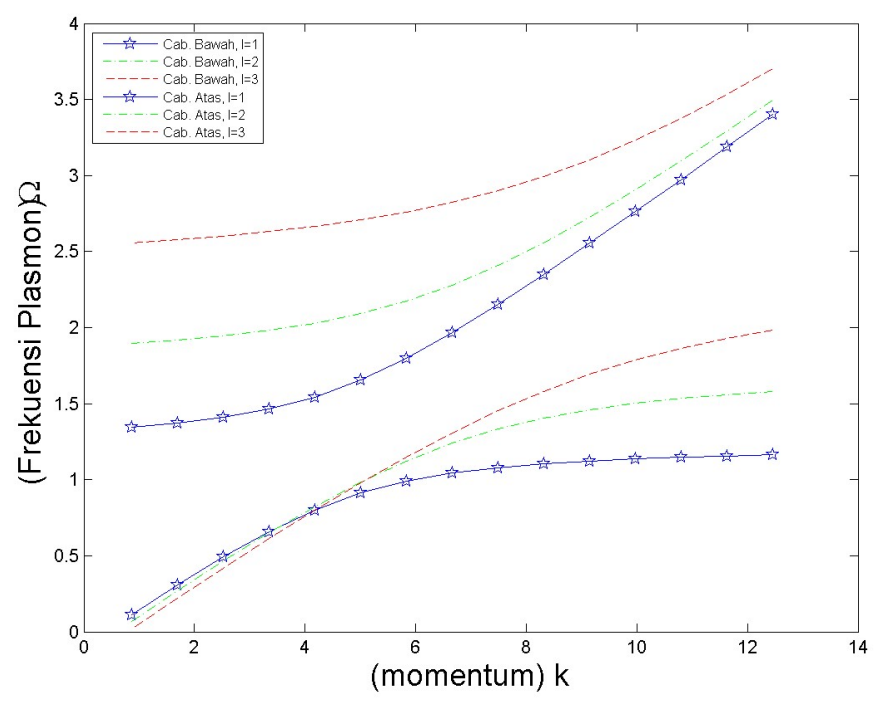

Gambar 2 Grafik hubungan dispersi untuk bilangan kuantum $l$ dari $l=1$ sampai dengan 3 .

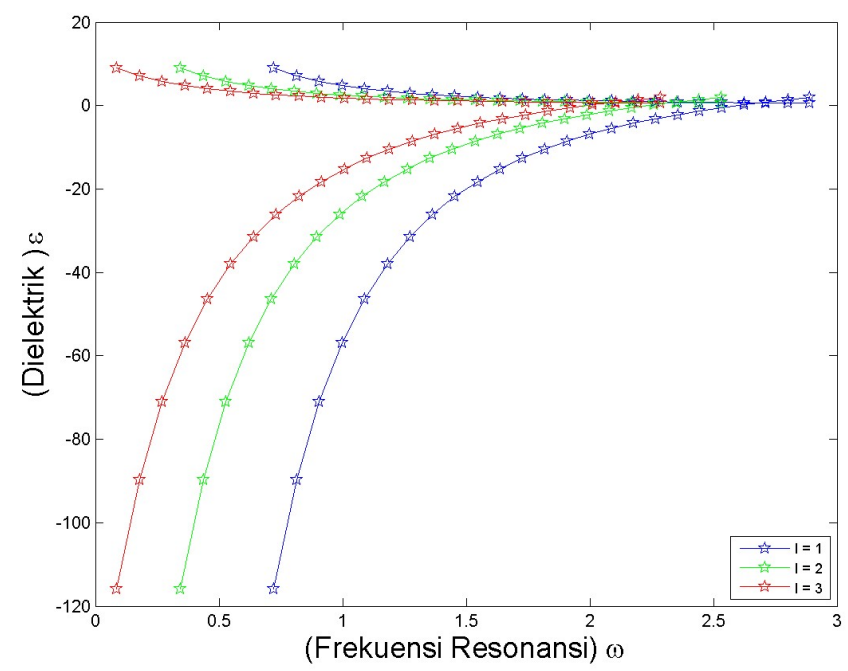

Gambar 3 Grafik gabungan $\varepsilon$ dielektrik : fungsi dielektrik logam riil dan imajiner terhadap frekuensi resonansi plasmonik. Dengan bilangan kuantum $l=1$ sampai dengan $l=3$.

Gambar 3 mendeskripsikan gabungan kurva dielektrik riil (tiga kurva bawah) dan imajiner (tiga kurva atas) terhadap FR. Pada nilai dielektrik $\varepsilon(\omega)$ sama dengan nol maka nilai keseluruhan frekuensi plasmon menuju nilai tak hingga. Pada frekuensi resonansi $\Omega_{\mathrm{l}=1 ; \epsilon=1,8 \mathrm{eV}}=1,95$ konstanta dielektrik imajiner memiliki nilai positif dari $\mathcal{\varepsilon}_{\text {im } \mathrm{l}=1 ; \epsilon=3.2 \mathrm{eV}}=9,07$, $\mathcal{E}_{\text {real } 1=1 ; \epsilon=1,8 \mathrm{eV}}=0,57$ dan $\Omega_{1=1 ; \epsilon=3.2 \mathrm{eV}}=0,57$ konstanta dielektrik riil memiliki nilai negatif dari $\mathcal{E}_{\text {im }} \mathrm{l=1; \epsilon =3.2 \textrm {eV }}=-18,20$ hingga $\Omega_{\mathrm{l}=1, \epsilon=3.2 \mathrm{eV}}=0,57$. Ini menunjukkan arah polarisasi medan dielektrik berlawanan dengan medan datang.

Kebergantungan ukuran partikel juga dapat berpengaruh terhadap besarnya momentum resonansi partikel akibat partikel foton seperti yang terlihat pada Gambar 4. variasi ukuran nanopartikel logam emas adalah $5 \mathrm{~nm}$ dan $10 \mathrm{~nm}$, pada ukuran $5 \mathrm{~nm}$ momentum plasmonik logam emas memiliki nilai yang lebih besar dibandingkan radius nanopartikel $10 \mathrm{~nm}$. Nilai momentum ternormalisasi $\left(k / k_{p}\right)_{1=1,2 ; \epsilon=30 \mathrm{eV}}=5,87$ pada $\Omega_{1=1 ; \epsilon=30 \mathrm{eV}}=1,16 \mathrm{eV}$ dan $\Omega_{\mathrm{l}=2 ; \epsilon=30 \mathrm{eV}}=1,58 \mathrm{eV}$.

Kemudian, pada saat radius nanopartikel $10 \mathrm{~nm}$ maka diperoleh FR plasmon yang lebih kecil dengan nilai $\left(k / k_{p}\right)_{1=1,2 ; \epsilon=30 \mathrm{eV}}=4,81$ pada $\Omega_{1=1 ; \epsilon=30 \mathrm{eV}}=1,16 \mathrm{eV}$ dan $\Omega_{1=2 ; \epsilon=30 \mathrm{eV}}=1,57 \mathrm{eV}$. 
Nanopartikel emas memiliki tingkat FR tinggi pada ukuran partikel yang lebih kecil, luas permukaan mempengaruhi absorpsi energi yang dialami oleh partikel. Jarak antarmuatan ketika polarisasi terjadi setelah interaksi (gelombang elektromagnet dengan bahan), mempengaruhi kecepatan/kemudahan polarisasi antar muatan berlawanan dalam nanopartikel emas.

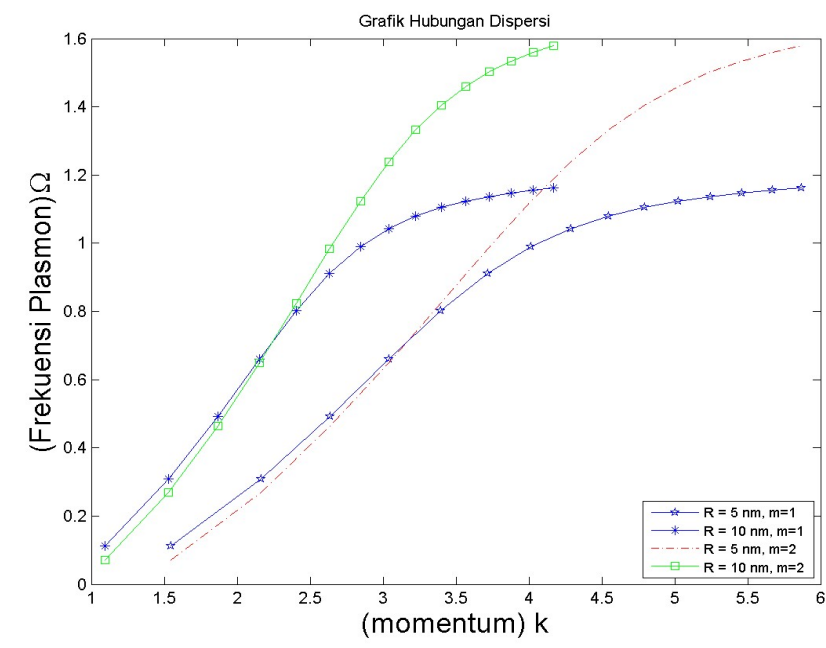

Gambar 4 Grafik hubungan dispersi antara frekuensi plasmon dengan momentum. Grafik di atas juga bervariasi terhadap radius $R$ dan bilangan kuantum $l$.

\section{KESIMPULAN}

Hubungan dispersi telah diperoleh dengan menggunakan persamaan KKH dan dengan mendiagonalisasi KKH dengan TB. Setiap keadaan memperoleh persamaan HD yang sama pada geometri planar dan nanowire. Perbedaannya adalah besar FR ternormalisasi cabang atas dan bawah adalah 3,2 eV pada NB emas $\Omega_{\mathrm{l}=1 ; U k} / \omega_{p}$ yaitu 3,7 dan $\Omega_{l=1, L k} / \omega_{p}=1,16$.. Nilai frekuensi resonansi paling rendah dihasilkan oleh material planar. Dan paling tinggi diperoleh pada nanologam bola emas dan nanowires. Terdapat perbedaan ketika nilai momentum di nanologam bola $k / k_{p} \geq 8$, nilai frekuensi plasmon ternormalisasi bernilai optimum $\quad\left(\Omega_{1=1 ; U k} / \omega_{p} \sim 1\right)$. Pada nanowires, ketika momentum gelombang vektor $k / k_{p} \sim 2$. Maka nilai frekuensi plasmon yang dinormalisasi optimum $\Omega_{\mathrm{Lk}} / \omega_{p} \sim 1$.

FR pada NB emas adalah $\Omega_{1=1 ; \epsilon=1,8 \mathrm{eV}}=2,04 \mathrm{eV}$. Sedikit berbeda dengan hasil yang diperoleh Dekarchova dkk (2016), energi frekuensi resonansinya adalah $\Omega_{1=1 ; \in=1,8 \mathrm{eV}}=2,27 \mathrm{eV}$.

Radius nanologam mempengaruhi vektor gelombang di permukaan plasmon dengan nilai $\left(k / k_{p}\right)_{R=5 n m}=5,87$ dan $\left(k / k_{p}\right)_{R=10 \mathrm{~nm}}=4,17$. Hasil ini selaras dengan apa yang dilakukan oleh Shopa (2013) dimana frekuensi resonansi semakin berkurang di permukaan ketika radius nanopartikel semakin besar karena resonansi juga berhubungan dengan vektor gelombang.

\section{DAFTAR PUSTAKA}

Brodin G., Marklund M., Stenflo L., Shukla, K.P., Dispersion relation for Electromagnetic Wave Propagation in a Strongly Magnetized Plasma, New Journal of Physics, 8, Issue $16,1-2,2006$.

Dekarchova A., Kolwas K., Demchenko I, Dielectric Function for Gold in Plasmonics Applications : Size Dependence of Plasmon Rsonance Frequencies and Damping Rates for Nanospheres, Journal : Plasmonics, 6-9, 2016.

Giangregorio, M.M., Jiao, W., Bianco, G.V., 2013, Insight into the Effects of Metal Nanostructuring and Oxidation on Work Function and Charge Transfer of Metal / Graphene hybrid, Journal : Nanoscale, 1-9, 2013.

Lan, P.T.N., Nga, T.D., Viet, A.N., Second Quantization Model for Surface Plasmon Polariton in Metallic Nanowires, Journal of Physics : Conference Series, 726,1-7, 2016. 
Nga, T.T.D., Lan, P.T.N., Viet, A.N., 2015, Second Quantization Model of Surface Plasmon Polariton at Metal Planar Surface, Journal of Physics : Conference Series, 627, 1-3, 2015.

Schider, G., Krenn, R.,J., Hohenau, A., Plasmon Dispersion Relation of Au and Ag Nanowires, Physical Review B, 68, 1, 2003.

Shopa, M., Imaging and Manifestation of Plasmons on Gold Spherical Nanoantennas in Near and Far Field Regions, Disertasi, Institute of Physics : Polish Academy of Sciences, Warsaw, 2013.

Stoof, C.T.H., Gubbles, B.K., Dickerscheid, M.B.D., Ultracold Quantum Fields, Springer, Berlin, 2009.

Zayats, V.A., Smolyaninov, I.I., Near-Field Photonics : Surface Plasmon Polaritons and Localized Surface Plasmons, J. Opt. A : Pure Appl. Opt., Issue 54, 2003. 